\section{Erosion Processes of the Discharge Cathode Assembly of Ring-Cusp Gridded Ion Thrusters} AIAA-2006-3558

Presented at the AIAA Plasma Dynamics Conference, San Francisco, 5-8 June 2006.

Alec D. Gallimore ${ }^{1}$ The University of Michigan, Ann Arbor, MI. 48109, USA

Joshua L. Rovey ${ }^{2}$ Starfire Industries, LLC, Champaign, IL 61820, USA

Daniel A. Herman ${ }^{3}$ QSS Group, Inc., Cleveland, OH.
44135, USA

Abstract: An ion thruster discharge cathode assembly (DCA) erosion theory is presented based on near-DCA NSTAR plasma measurements and experimental results for propellant flow rate effects on ion number density. The plasma potential structures are utilized in an ion trajectory algorithm to determine the location and angle at the DCA keeper of bombarding ions. These results suggest that the plasma potential structure causes a chamfering of the DCA keeper orifice. Results from tests with an instrumented DCA show that increasing DC propellant flow rate causes a decrease in "keeper" orifice ion number density, most likely due to charge-exchange and elastic collisions. Combining these two results, the known wear-test and extended life test (ELT) DCA erosion profiles can be qualitatively explained. Specifically, the change in the wear profile from the DCA keeper downstream face to the keeper orifice for the ELT may be a result of the reduction in DCA propellant flow rate when the thruster operating point is changed from the TH 15 to TH 8.

\footnotetext{
${ }^{1}$ Aurthur F. Thurnau Professor, Department of Aerospace Engineering, Associate Fellow AIAA.

${ }^{2}$ Research Engineer, Member AIAA .

${ }^{3}$ Research Engineer, On-board Propulsion Branch, Member AIAA
}

\section{Introduction}

Gridded ion thrusters are high-specific impulse, high-efficiency, advanced space propulsion systems. Three main processes compose gridded ion thruster operation: 1) electron generation; 2) ion production through electron bombardment ionization; and 3) ion extraction using high-voltage grids (ion optics). In modern ion thrusters, electrons are generated with a hollow cathode called the discharge cathode because it initiates and sustains the plasma discharge. Electrons from the cathode enter the discharge chamber and create ions through electron bombardment ionization collisions with neutral atoms, typically xenon. Plasma production is enhanced by increasing the electron pathlength with a magnetic field. Early gridded thrusters utilized divergent and radial magnetic field configurations, but modern, state-of-the-art thrusters utilize a ringcusp geometry because it provides better plasma containment. ${ }^{1}$ Ions are extracted and accelerated to significant velocity by high-voltage grids. One prominent example of a contemporary state-of-the-art ring-cusp gridded ion thruster is the 30 -cm-diameter NASA Solar Technology and Application Readiness (NSTAR) ion thruster utilized on the Deep Space One (DS1) spacecraft.

Three wear-tests performed on a 30-cm-diameter thruster as well as the extended life test (ELT) of the flight spare DS1 thruster have shown that extended ion thruster operation leads to ion bombardment sputter erosion of the discharge cathode. ${ }^{2-10}$ During the first wear-test, severe erosion of the discharge cathode was noted ${ }^{2}$ that if left unchecked would have jeopardized the DS1 mission. A keeper electrode that is maintained at an intermediate potential between the discharge cathode and the anode was added to the discharge cathode to serve as a sacrificial shield. The combination of the discharge cathode with the keeper is called the discharge cathode assembly (DCA). The subsequent 1000 -hr and 8200-hr wear-tests showed erosion of the DCA occurring primarily from the downstream keeper face at approximately the 50\% keeper radius. However, during the ELT, the primary erosion location shifted from the $50 \%$ keeper radius to the keeper orifice. This shift and an accelerated erosion rate coincided with two ELT events: a throttling down in thruster power; and an inadvertent shorting event between discharge cathode keeper and cathode common. An experimental investigation by Kolasinski found evidence that the erosion location shifted when the thruster was operated at a reduced beam current condition; i.e., when the thruster was adjusted from the nominal high-power TH 15 condition to the lower-power TH 8 operating point. ${ }^{11}$ Nominal operating conditions for the NSTAR 
thruster are shown in Table 1. Note the reduction in DCA mass flow rate from TH 15 to TH 8.

\begin{tabular}{|ccc|}
\hline $\begin{array}{c}\text { Operating } \\
\text { Point }\end{array}$ & $\begin{array}{c}\text { Input Power } \\
(\mathrm{kW})\end{array}$ & $\begin{array}{c}\text { DCA Mass Flow } \\
\text { Rate }(\mathrm{mg} / \mathrm{s})\end{array}$ \\
\hline $\mathrm{TH}^{\mathrm{c}}$ & 0.5 & 0.24 \\
$\mathrm{TH}^{\mathrm{c}}$ & 1.0 & 0.24 \\
$\mathrm{TH} 8^{\mathrm{c}}$ & 1.4 & 0.24 \\
$\mathrm{TH} 10^{\mathrm{c}}$ & 1.7 & 0.25 \\
$\mathrm{TH} 12^{\mathrm{c}}$ & 1.8 & 0.26 \\
$\mathrm{TH} 15^{\mathrm{c}}$ & 2.3 & 0.36 \\
\hline
\end{tabular}

Table 1:Selected NSTAR ion thruster nominal operating parameters.

In an effort to understand better the erosion processes affecting the DCA, the University of Michigan Plasmadynamics and Electric Propulsion Laboratory has investigated a $30-\mathrm{cm}$-diameter ringcusp gridded ion thruster. Specifically, this investigation attempts to determine and explain the physical processes responsible for DCA erosion. The investigation is divided into three main parts that correspond with the main sections of this paper. First, an experimental effort to measure thruster internal plasma properties with beam extraction is described. Second, experimental results are used to calculate the DCA erosion rate and determine the importance of doubly-charged ions. Third, internal plasma properties are utilized to numerically simulate keeper wear-profiles for the TH 15 and $\mathrm{TH} 8$ operating conditions. The conclusions section summarizes the physical processes causing DCA erosion.

\section{Discharge Chamber Plasma Properties}

The research presented in this paper utilized the FMT2 ion thruster, which is a derivative of the NSTAR ion engine. The Functional Model Thruster (FMT) series preceded the NSTAR Engineering Model Thrusters (EMTs), and the NSTAR flight thrusters (FTs). All three variants are based on the 30-cm-diameter ring-cusp ion engine developed by NASA in the 1980s. The FMT2 has been shown to exhibit a nearly identical magnetic field topology compared to the EMTs and FTs. Furthermore, the FMT2 performance is essentially identical to that of the FTs. More detailed information on the FMT2 can be found in References 12-18. Under research grants from the NASA Glenn Research Center (GRC), Williams modified the FMT2 thruster to permit Laser-Induced Fluorescence (LIF) interrogation of the discharge plasma by putting three quartz window covered rectangular slots into the anode wall (Figure 1). ${ }^{15,17}$ Follow-on tests showed that these modifications did not alter the discharge chamber magnetic field, ion production efficiency, or overall thruster performance. ${ }^{15-17}$
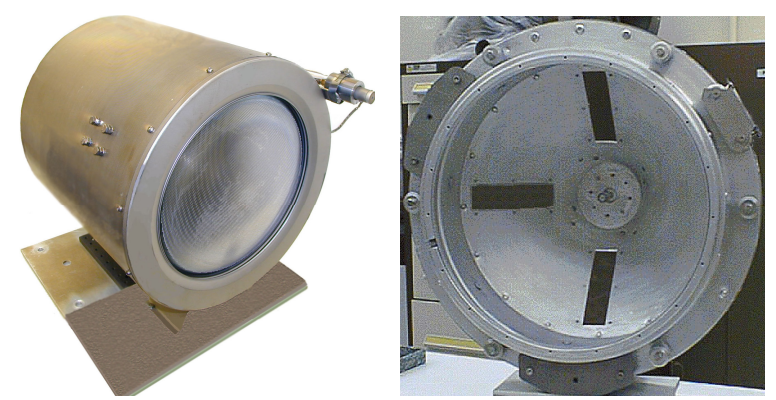

Figure 1: FMT2 thruster (left) and FMT2 discharge chamber illustrating rectangular slots (right).

Williams' LIF experimental setup was further modified to allow internal electrostatic probing of the discharge plasma. The side anode quartz window is replaced by a discharge plasma containment mechanism permitting probe access inside the anode over a two-dimensional grid. The discharge plasma containment mechanism is described in detail in References 12-14,19, and 20.

Local plasma potential measurements are obtained utilizing a floating emissive probe. ${ }^{21-23}$ Electron emission from "hot" electrostatic probes provides a means to measure the local plasma potential directly. This measurement resolves many problems encountered with interpretation of the "knee" of the I-V potential from single Langmuir probes. ${ }^{24-26}$ Langmuir I-V characteristics are complicated by probe geometry, magnetic fields, the presence of a flowing plasma, and ionization near the probe. $^{22}$ Emitting probes offer an alternative technique to determine the plasma potential that is less sensitive to plasma conditions.

While plasma potential measurements have been obtained over a variety of thruster operating conditions (Table 2), only results for the TH 8 and TH 15 operating conditions will be presented here. ${ }^{13,19,20}$

\begin{tabular}{|c||c|c|c|c|c|c|c|c|c|}
\hline \multirow{2}{*}{$\begin{array}{c}\text { NSTAR } \\
\text { TH Level }\end{array}$} & $\begin{array}{c}\text { Input } \\
\text { Power }\end{array}$ & $\begin{array}{c}\text { Specific } \\
\text { Impulse }\end{array}$ & $\begin{array}{c}\text { Discharge } \\
\text { Voltage }\end{array}$ & $\begin{array}{c}\text { Discharge } \\
\text { Current }\end{array}$ & $\begin{array}{c}\text { Disch. } \\
\text { cathode } \\
\text { flow }\end{array}$ & $\begin{array}{c}\text { Main } \\
\text { flow }\end{array}$ & $\begin{array}{c}\text { Beam } \\
\text { Voltage }\end{array}$ & $\begin{array}{c}\text { Beam } \\
\text { Current }\end{array}$ & $\begin{array}{c}\text { Accel } \\
\text { Voltage }\end{array}$ \\
\hline \hline TH 15 & 2.29 & 3120 & 25.14 & 13.13 & 3.70 & 23.43 & 1100 & 1.76 & -180 \\
\hline TH 12 & 1.94 & 3174 & 25.40 & 10.87 & 2.89 & 19.86 & 1100 & 1.49 & -180 \\
\hline TH 8 & 1.44 & 3109 & 25.10 & 8.24 & 2.47 & 14.41 & 1100 & 1.10 & -180 \\
\hline TH 4 & 0.97 & 2935 & 25.61 & 6.05 & 2.47 & 8.30 & 1100 & 0.71 & -150 \\
\hline TH 0 & 0.47 & 1972 & 25.20 & 4.29 & 2.47 & 5.98 & 650 & 0.51 & -150 \\
\hline
\end{tabular}

Table 2:Selected NSTAR ion thruster throttle table nominal operating parameters.

The plasma potential contours shown in Figure 2 for both TH 8 and TH 15 demonstrate an on-axis minimum region indicating the plume structure of the 
discharge cathode. Plasma potentials inside this lowpotential column are only 16 volts near the discharge cathode. The potential drop is highest at the cathode orifice because the axial magnetic field is strongest there and effectively impedes the diffusion of electrons in the radial direction. The potential increase in the radial direction indicates a freestanding potential gradient that forms the transition between the discharge cathode plume and the main discharge plasma.

Evaluation of the centerline plasma potential values does not support the existence of a potentialhill structure at the operating conditions investigated, which has been one of the proposed causes of anomalous discharge cathode erosion. ${ }^{27}$ Considering the importance of the magnetic field in shaping the discharge environment, it is not surprising that a potential-hill is not present. While the magnetic field reduces radial diffusion, the axial magnetic field enhances axial diffusion of electrons, which would tend to smooth out potential structures on axis. This is particularly true in regions near the discharge cathode where the axial magnetic field is largest.

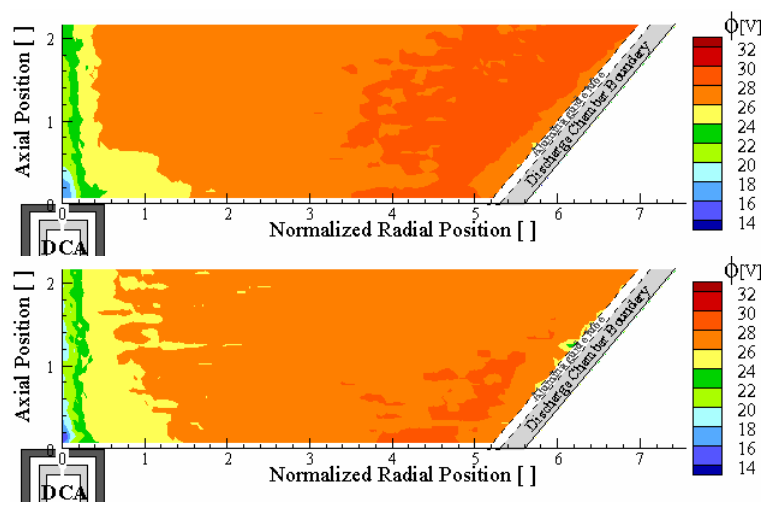

Figure 2: FMT2 floating emissive probe plasma potential contours for TH 8 (top) and TH 15 (bottom).

Comparison of the two contours in Figure 2, or any of the plasma potentials obtained for approximately the same discharge voltage for that matter, shows negligible variations in the plasma structure at various operating conditions. It should be noted that shorting of the discharge keeper to discharge cathode common was also investigated to determine what effect the ELT keeper shorting event had on DCA erosion. Perhaps not surprisingly, keeper shorting did not have a significant effect on the near-DCA plasma structure outside of the keeper sheath. ${ }^{13,19}$

A closer look at the near-DCA plasma contours (Figure 3) for both $\mathrm{TH} 8$ and $\mathrm{TH} 15$ highlights an important finding; the high-density, low-plasma potential plume structure is distinctly different from the bulk discharge plasma. Large radial potential gradients exist because of the largely axial magnetic field topology near the DCA. This free-standing gradient structure is termed a double layer. Double layers form the transition between two plasmas that are at two different potentials. A double layer forms the boundary between the discharge cathode plume and the bulk discharge plasma. ${ }^{28-30}$ The magnetic field, potential gradients, and double layer are all tied together. The magnetic field reduces radial electron motion, creating the potential gradient in the radial direction and the high density plume along centerline.
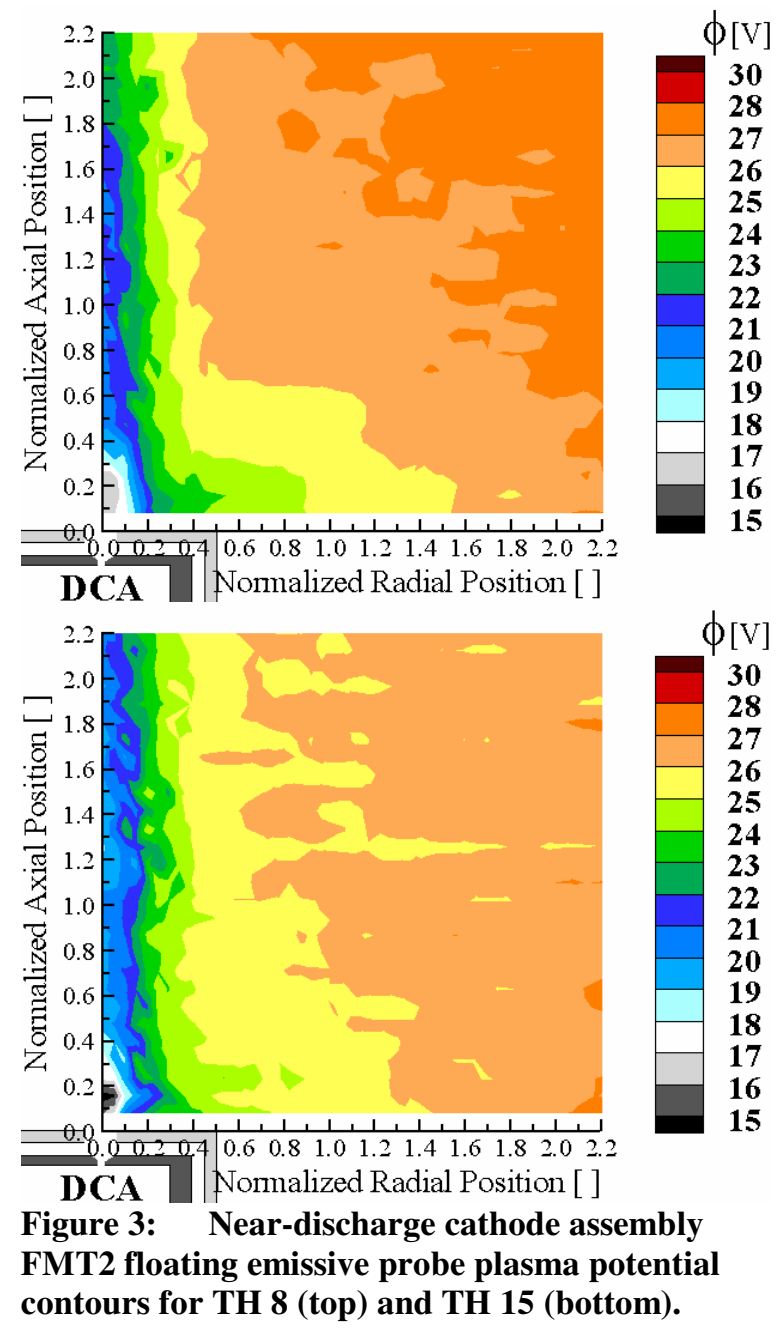

Near the cathode keeper, there is a potential difference of approximately 10 volts across the double layer, which roughly spans the length from cathode centerline to the discharge keeper plate radius. The difference in cathode keeper and cathode common potential is $5-7$ volts for these operating conditions. Combining the potential drop through the discharge plasma with a non-shorted keeper sheath 
fall yields an accelerating potential of approximately $20-21$ volts.

\section{DCA Erosion Rate Calculations}

The application of the measured plasma potentials to calculate DCA erosion rates is difficult due to the lack of an accurate low-energy, heavy-ion sputter yield description. Recently, experimental data taken by Doerner, et al. reported sputter yield data for $\mathrm{Xe}^{+}-\mathrm{Mo}$ with ion bombardment energies from 10 to $200 \mathrm{eV}^{31,32}$ The spectroscopic sputter yields and standard weight loss yields calculated by Doerner compare nicely to each other and to existing lowenergy $\mathrm{Xe}^{+}$-Mo data taken by other researchers, thus validating Doerner's results. A sixth-order polynomial fit was made to a log-log plot of the Doerner sputter yield versus energy data. From this fit, an empirical determination of the normal incident sputtering yield of the low-energy $\mathrm{Xe}^{+}-\mathrm{Mo}$ system is determined as a function of energy (Equation 1). Doerner's results indicate a normal threshold energy of $\sim 15 \mathrm{eV}$ for xenon sputtering of molybdenum. ${ }^{32}$

$$
\begin{aligned}
Y_{\text {Doerner }}(E) & =\exp \left\{-0.372304[\ln (E)]^{6}+9.48041[\ln (E)]^{5}\right. \\
-100.046[\ln (E)]+560.276[\ln (E)]^{3}-1758.24[\ln (E)]^{2} & \\
& +2940.48[\ln (E)]-2064.3\}
\end{aligned}
$$

In Equation 1, $Y$ is the sputtering yield and $E$ is the energy of the incident sputtering ion. Numerous investigations have shown that sputtering yields have an angular dependence. ${ }^{33-38}$ Yamamura's empirical formula for the angular dependence of sputtering, specifically for the low-energy $\mathrm{Xe}^{+}-\mathrm{Mo}$ system, is given as: ${ }^{36,39}$

$$
\left(\frac{Y(\theta)}{Y(0)}\right)=\cos ^{-19.96} \theta \cdot \exp \left[-13.55\left(\cos ^{-1} \theta-1\right)\right] \cdot \quad \text { Eqn. } 2
$$

In Equation 2, the numeric factors are energydependent fit parameters determined from $100-\mathrm{eV}$ xenon ions impacting a molybdenum target, $Y(0)$ is the sputtering yield at normal incidence, and $\theta$ is the angle of incidence relative to the target surface. ${ }^{39}$ The exponent fit parameter, 19.96, carries the threshold effect and is a function of the ratio $E / E_{t h}$. Yamamura's formula will be utilized over other formulas because it is based upon low-energy data as opposed to empirical formulas that are generic to multiple incident particle-target systems and/or rely heavily on extrapolation from high-energy data. Combining Equations 1 and 2, the sputtering yield as a function of incident particle energy and angle is determined. The minimum threshold energies as a function of incident angle for the $\mathrm{Xe}^{+}$-Mo system is 8 $\mathrm{eV}$, which occurs at $48^{\circ}$.

Two additional pieces of information are required before an erosion rate calculation based on measured plasma potentials can be made: the incoming particle angle of incidence, and the number of particles impacting the keeper face. Based upon LIF measured velocimetry on the FMT2, an incident presheath angle of approximately 60 degrees (with respect to the keeper normal) is most likely. ${ }^{15-18}$

The ion is assumed to be accelerated through the sheath normal to the surface by the potential difference between the presheath potential of 22 volts and the discharge keeper floating potential (5-7 volts). A through-sheath energy and angle is calculated giving the incident ion energy with angular dependence. The effect of shorting the cathode keeper to cathode common can also be investigated by reducing the keeper floating potential to 0 volts.

The number of incident ions can be estimated from the number density measurements made over the same spatial domain as the plasma potential measurements. Ion number densities are measured with a Langmuir probe utilizing a thin-sheath analysis with a sheath thickness correction algorithm. $^{13,14,19}$ The ion number density just outside the double layer, approximately a keeper radius from the cathode centerline and in the plane of the keeper face in the radial and axial directions is roughly $5 \times 10^{11} \mathrm{~cm}^{-3} .^{13,19}$ The flux of ions towards the keeper is assumed to be a directed drift with an energy corresponding to the fall voltage, given below:

$$
\text { ion flux }=n_{\text {ion }} \sqrt{\frac{2 e\left(\phi_{p}-\phi_{C K}\right)}{M_{X e}}} . \quad \text { Eqn. } 3
$$

In Equation $3,\left(\phi_{P^{-}} \phi_{C K}\right)$ is the difference in potentials between the plasma outside the double layer and the discharge cathode keeper floating potential. The keeper erosion rate is then calculated as the yield from Doerner's data fit as a function of incident energy and angle multiplied by the ion flux times the number density of the molybdenum target. The calculated erosion rates for $\mathrm{TH} 15$ with only singly-ionized xenon are $8 \mu \mathrm{m} / \mathrm{khr}$ and $49 \mu \mathrm{m} / \mathrm{khr}$ for the cathode keeper floating and shorted to common, respectively. ${ }^{19}$ Since plasma potentials are roughly equivalent for TH 8 and TH 15 conditions, erosion rates are similar. The measured erosion rates for the 1000-hr and 8200-hr NSTAR wear tests were 70 $\mu \mathrm{m} / \mathrm{khr}$ and $63 \mu \mathrm{m} / \mathrm{khr}$, respectively. ${ }^{5,6,40,41}$ The first $5,850 \mathrm{hrs}$ of the ELT had an estimated erosion rate of $77 \mu \mathrm{m} / \mathrm{khr}$ and an estimated accelerated rate of 173 
$\mu \mathrm{m} / \mathrm{khr}$ after the shorting event and throttling down to $\mathrm{TH} 8 .^{19,42-46}$ The erosion rates calculated from the measured plasma parameters assuming only singlyionized xenon are considerably less than the measured wear test erosion rates, which indicates that the analysis has not accurately accounted for all of the dominant factors in DCA erosion.

It appears as though the shorting event of the ELT did significantly contribute to the increased erosion observed in this wear test. The effect of shorting the discharge cathode keeper to cathode common does have a significant effect on the calculated erosion rates, resulting in an increase of roughly a factor of four for the conditions investigated.

A major simplification in the above erosion calculation is that it does not account for the increased erosion caused by double-ionized xenon. The ratio of the double-to-single ion current ratio near the DCA is unknown. Traditionally, the measured double-to-single ion currents in the plume have been used to estimate the double-to-single number density ratio inside the engine. A range of values has been measured in the plume of the NSTAR thrusters for the double-to-single ion current: $0.02-0.34 .^{42,47,48}$ A doubly-charged ion would carry a charge of twice the singly-ionized xenon ion and would therefore be accelerated to twice the energy for a given electric field. The double-to-single current ratio is converted to a number density for each species taking into account that the double ion current accounts for each double ion twice and the dependence of ion velocity with charge state assuming constant accelerating potentials. A fixed double-to-single number density ratio of 0.20 is used in this analysis because it is consistent with measured values in the plume at the high-power range of the NSTAR throttling table. ${ }^{48}$ While this value is on the high end of the double-to-single ion ratio measured in the plume, this value is likely to be representative of the plasma state near the DCA given the proximity to the ionization source.

When the doubly-charged ions are accounted for, the calculated erosion rate increases as expected. For a double-to-single ratio of 0.20 , the measured total ion number density of $5 \times 10^{11} \mathrm{~cm}^{-3}$, and a local plasma potential of 27 volts outside the double layer, the calculated erosion rate from Doerner's data fit is $54 \mu \mathrm{m} / \mathrm{khr}$ for the standard keeper voltage and 165 $\mu \mathrm{m} / \mathrm{khr}$ when the keeper is shorted to the cathode. ${ }^{19}$ These new values are strikingly close to the ELT estimated erosion rates noted above and suggest that the keeper shorting, in combination with the presence of doubly-charged xenon ions, contributed significantly to the large DCA erosion observed in the ELT.
It follows from the above erosion calculation that because only the number densities increased slightly as the engine is throttled to higher-power and the plasma potential mappings depend primarily on discharge voltage only, the erosion rate is expected to increase slightly as the engine is throttled to higherpower. There is no reason to expect, based upon this erosion analysis alone that TH 8 would result in an increased erosion rate compared to TH 15. Therefore, additional factors must account for the observed ELT DCA erosion pattern.

\section{Keeper Wear-profiles}

The plasma potential results for TH 15 and TH 8 (Figures 2 and 3 ) are coupled with an erosion rate calculation to numerically simulate keeper wear. Flow rate effects are then incorporated to qualitatively predict wear-profiles for $\mathrm{TH} 15$ and $\mathrm{TH}$ 8.

\section{A. Ion Trajectory Calculation}

As noted above, an ion trajectory calculation is utilized to determine the bombarding ion impact angle, energy, and location at the keeper downstream face. The trajectory simulation procedure consists of five main steps: 1) load the plasma potential maps of the $30-\mathrm{cm}$ thruster described above; 2) calculate the electric field produced by the variation of plasma potential with spatial location; 3) determine initial conditions for a simulation ion; 4) iteratively calculate the ion trajectory based on the initial conditions; and 5) determine if the ion impacts the keeper and, if so, at what impact location, energy, and angle.

Since the TH 8 and TH 15 throttle points are of primary importance for comparison with the ELT, keeper wear-profiles are simulated only for these two conditions. The experimental plasma potential measurements are interpolated onto a $1 \mathrm{~mm}$ by $1 \mathrm{~mm}$ grid such that the entire computational domain has 4400 grid points. The electric field is calculated by using the plasma potential at the six adjacent grid points.

Table 3 shows the ion initial conditions investigated. A single simulation has 35,200 ions with 4400 initial positions (an ion starts from each of the computational domain grid points) and 8 initial angular orientations. Angular orientations of 0 degrees and 90 degrees correspond to an initial velocity in the radial and axial directions, respectively. Simulations are completed for both warm and cold ions, as well as singly- and doublycharged ions. Warm and cold ions are assumed to 
have initial energies of $5 \mathrm{eV}$ and $0.05 \mathrm{eV}$, respectively. ${ }^{49}$

\begin{tabular}{|ll|}
\hline Locations & 4400 points $(\Delta \mathrm{x}=1.0 \mathrm{~mm})$ \\
\hline Charge-state & singly, doubly \\
\hline Initial Energy $(\mathrm{eV})$ & Warm $(5 \mathrm{eV})$ \\
(velocity) & Cold $(0.05 \mathrm{eV})$ \\
\hline Angular & $0,45,90,135,180,225$, \\
Orientation (deg.) & 270,315 \\
\hline
\end{tabular}

\section{Table 3: Ion initial conditions}

Starting with the initial conditions, an ion trajectory is calculated by iterating through the Lorentz force equation. For the simulations presented here, the magnetic field inside the ion thruster is assumed to have a negligible impact on ion motion. This assumption is justified because the ion cyclotron radius is significantly larger than the thruster dimensions. The trajectory calculation iterative procedure loop is as follows: 1) interpolate the electric field at the ion position; 2) calculate the new velocity components; 3 ) determine the new spatial location by assuming the new velocity components are constant over the time step; and 4) repeat. This procedure loop is iterated until the ion exits the computational domain. If the ion exit position is at the DCA keeper, then the ion location and velocity are recorded, and the bombarding angle is calculated. These computations calculate the pre-sheath angle, pre-sheath velocity, and pre-sheath location of each ion. Examples of ion trajectories through the calculated electric field profile are shown in Figure 4. Note that three of the six ions impact the keeper.

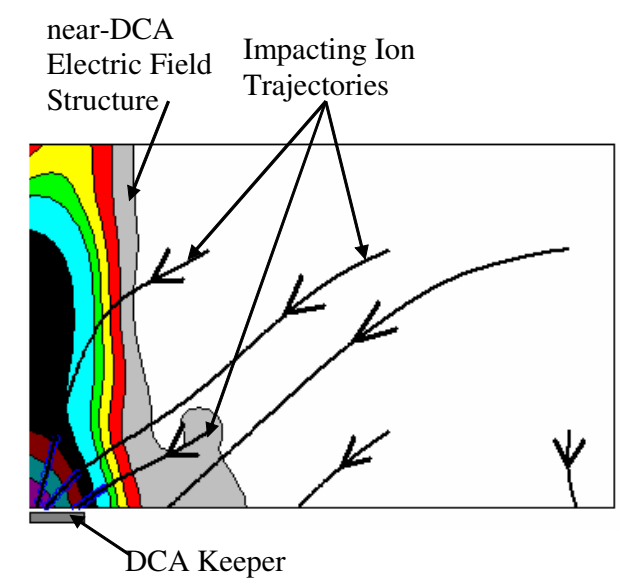

Figure 4: Example ion trajectories through the calculated electric field profile.

\section{B. Erosion Calculation}

Ions first pass through the keeper sheath before impacting so the through-sheath impact location, angle, and energy must be determined. An ion is assumed to translate essentially axially through the sheath. Therefore, the through-sheath impact location is equivalent to the pre-sheath location. This assumption is justified by the small thickness of the sheath and the small radial electric fields expected within the sheath. The pre-sheath radial velocity is assumed constant through the sheath and the axial velocity component is assumed to increase correspondingly with the gain in energy through the keeper sheath potential drop. The angle of the vectoral sum of these two velocity components constitutes the through-sheath impact angle. The measured near-DCA plasma potential $(\sim 14 \mathrm{~V})$ minus the floating keeper potential $(\sim 5 \mathrm{~V})$ determines the keeper sheath potential drop of $\sim 9 \mathrm{~V}$. The bombarding ion energy is calculated as the ion kinetic energy using the through-sheath velocity components.

Utilizing the through-sheath impact angle and energy, the number of sputtered atoms for each incident ion is calculated with the equations presented above (Equations 1 and 2). Summing over all the ions that impact the keeper provides the number of sputtered atoms as a function of radial location on the keeper faceplate, which yields the simulated keeper wear-profiles discussed below.

\section{Simulated Keeper Wear-profile Results}

Figure 5 shows simulated keeper wear-profiles for the warm $(5 \mathrm{eV})$ and cold ion $(0.05 \mathrm{eV})$ assumptions for the $\mathrm{TH} 15$ and $\mathrm{TH} 8$ thruster operating conditions. Doubly-charged ions tend to increase the magnitude of the profile, but have no effect on the shape. The warm ion assumption results in less erosion of the keeper than the cold ions because higher-energy ions are capable of escaping from the near-DCA low plasma potential region, while less-energetic cold ions are more easily pulled into the keeper by the potential field. Because Williams ${ }^{15}$ measured ion temperatures of $0.75 \mathrm{eV}$ in the near-DCA discharge chamber plasma of the FMT2, the true erosion profile is assumed to be closer to the cold ion results.

Both the TH 15 and $\mathrm{TH} 8$ results predict an erosion profile that leads to chamfering of the keeper orifice. The increase in erosion at the keeper orifice ( $\sim 25 \%$ keeper radius) leads to a chamfering profile that causes the orifice diameter to increase until the entire keeper face is eroded. This analysis suggests that the plasma potential structure causes the primary erosion location to be at the DCA keeper orifice. However, results from the 1000-hf and 8200-hr weartests show the dominant erosion location to be at the $50 \%$ keeper radius location. Furthermore, Kolasinski has shown that the primary erosion location shifts 
from the $50 \%$ radius to the orifice when thruster operation is adjusted from $\mathrm{TH} 15$ to $\mathrm{TH} 8 .{ }^{11}$ Therefore, based on the simulated keeper wearprofile results, the near-DCA plasma potential structure alone cannot be causing the known erosion results.
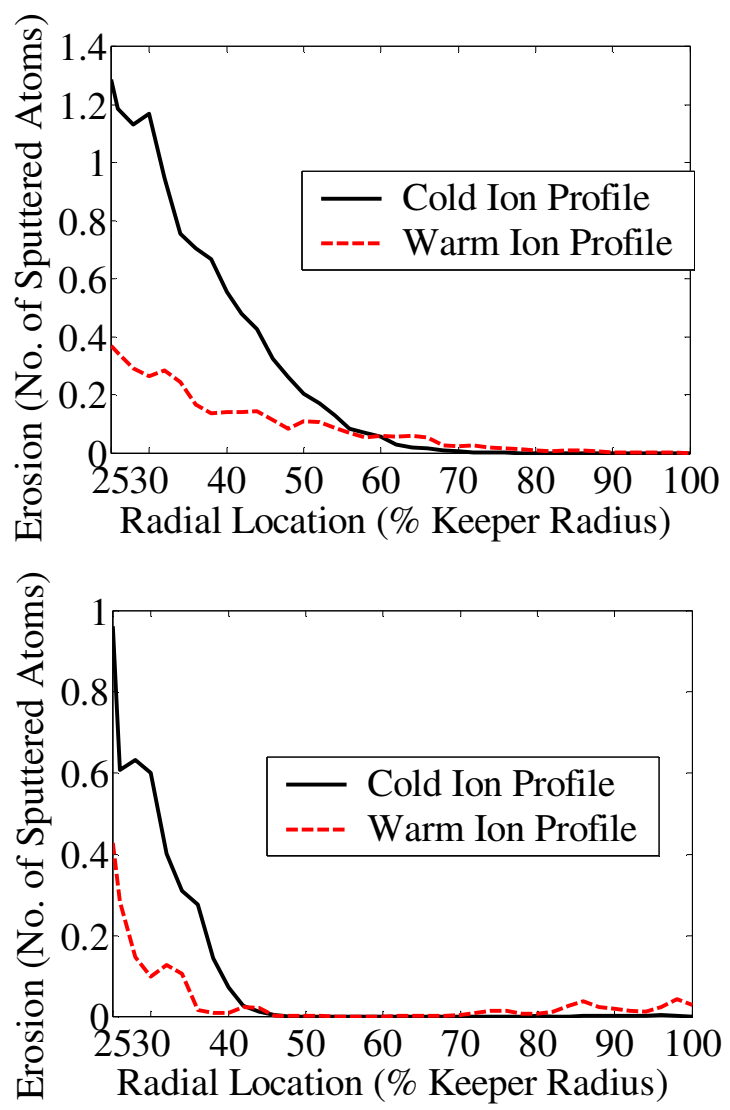

Figure 5: Simulated erosion profiles for the warm and cold ion assumptions for TH 15 (top) and TH 8 NSTAR (bottom) plasma potential maps.

\section{Propellant Flow Rate Effects}

A multiple-cathode discharge chamber $(\mathrm{MCDC})^{50,51}$ ion thruster developed jointly by GRC and PEPL has been used to predict the effects of propellant flow rate on near-DCA plasma properties. The MCDC is a rectangular discharge chamber designed to increase gridded ion thruster operational lifetime by operating three DCAs sequentially. Therefore, at any time, the MCDC contains an active DCA and two dormant cathodes. An experimental investigation with the MCDC studied the effect of propellant flow rate on plasma properties near the dormant cathode orifice. The dormant cathode appears similar to the DCA, but is outfitted with five planar Langmuir probes (Figure 6). One probe is located in the dormant cathode orifice and the other four are spaced symmetrically about centerline at the $50 \%$ keeper radius.

Results reported in Figure 6 are for the probe located in the keeper orifice (Probe 14) and the probes located at the 50\% keeper radius location. Similar results are obtained for different MCDC operating configurations. Results indicate that the number density at the orifice decreases by approximately $20 \%$ when the propellant flow is adjusted from zero to the full DCA flow rate (5.73 sccm). However, the ion number density at the 50\% keeper radius is relatively unaffected. Results suggest that propellant flow through the dormant cathode may be shielding the orifice from bombarding ions through elastic and charge-exchange (CEX) collisions, where the latter are known to cause changes in near-DCA ion energy distributions when a gas flow is present. ${ }^{52}$
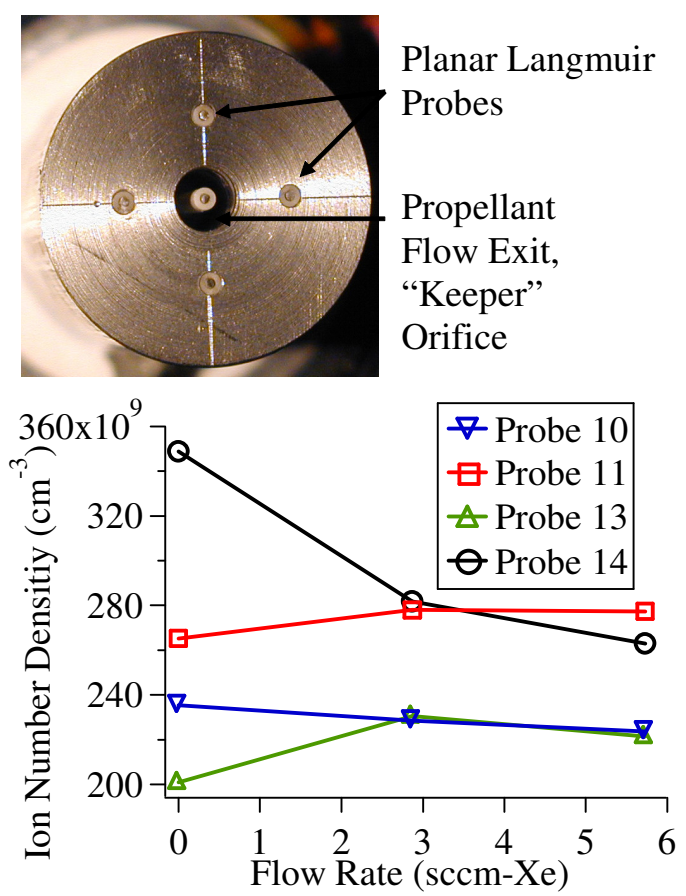

Figure 6: Instrumented dormant cathode (top) and ion number density as a function of propellant flow rate (bottom). Note the orifice probe (Probe 14) and 50\% keeper radius probes.

Further verification of the presence of CEX collisions at the DCA orifice is obtained by evaluating the CEX mean free path (MFP). Assuming the neutral temperature at the DCA keeper orifice is $1000 \mathrm{~K}^{53}$ and the velocity is equal to the sound speed, the keeper orifice neutral pressure is calculated using the conservation of mass. If the bombarding ions are assumed to have a kinetic energy equal to the plasma potential $(\sim 27 \mathrm{~V})$, the CEX collisions cross-section is 
equal to $45 \AA^{254,55}$ and the CEX MFP is $1.5 \mathrm{~mm}$ and $1.0 \mathrm{~mm}$ for the TH 8 and TH 15 operating conditions, respectively. These results are summarized in Table 4. Because the CEX MFP is the same order of magnitude as the keeper orifice diameter, these results suggest that CEX collisions are occurring near the orifice, with a smaller CEX MFP and, therefore, more CEX collisions, during operation at TH 15.

\begin{tabular}{|lcc|}
\hline $\begin{array}{l}\text { Operating } \\
\text { Condition }\end{array}$ & $\mathrm{TH} 8$ & $\mathrm{TH} 15$ \\
\hline$\dot{m}(\mathrm{mg} / \mathrm{s})$ & 0.24 & 0.36 \\
$\mathrm{p}(\mathrm{Pa})$ & 14.9 & 22.3 \\
$\mathrm{p}(\mathrm{mTorr})$ & 111.8 & 167.3 \\
$\mathrm{n}_{\mathrm{n}}\left(\mathrm{m}^{-3}\right)$ & $1.1 \times 10^{21}$ & $1.6 \times 10^{21}$ \\
$\lambda_{\mathrm{CEX}}(\mathrm{mm})$ & 1.5 & 1.0 \\
\hline
\end{tabular}

Table 4:NSTAR DCA keeper orifice neutral pressure, number density, and CEX MFP calculation results.

\section{E. TH 15 and TH 8 Qualitative Wear-profiles}

Keeper wear-profiles are qualitatively predicted by combining the trends obtained with the simulation results from Figure 5 and the propellant flow rate effects highlighted in Figure 6. TH 15 is the highpower, higher-flow rate condition (Table 1). Figure 7 shows the predicted erosion profile for TH 15 . Near the DCA keeper orifice, the bombarding ion number density and bombarding energy are reduced due to CEX collisions with expelled neutral propellant. As the radial distance from the orifice increases, the neutral density and corresponding number of CEX collisions decreases, leading to an increase in erosion. At approximately the $50 \%$ keeper radius, the effects of propellant flow rate are no longer present. Therefore, the $50 \%$ keeper radius corresponds to the maximum erosion point. At larger radial locations the erosion profile corresponds with the wear-profile simulation results that exclude propellant flow effects.

The TH 8 operating point uses less DCA propellant flow than TH 15 (0.24 vs. $0.36 \mathrm{mg} / \mathrm{s})$. The reduction in DCA flow rate reduces the keeper orifice neutral density and, therefore, the ability of the DCA orifice to protect itself from bombarding ions through CEX collisions. The TH 8 erosion profile is identical to the wear-profiles predicted by these simulations (Figure 7).
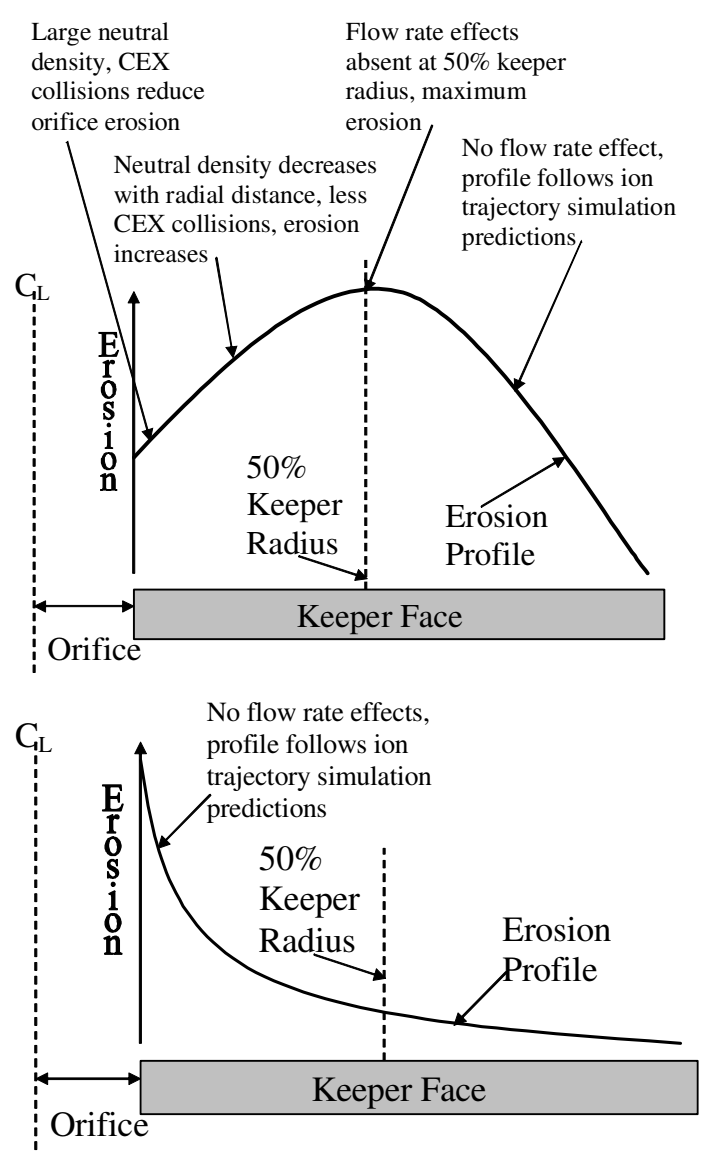

Figure 7: Qualitative erosion profile predictions for TH 15 (top) and TH 8 (bottom).

\section{Conclusions}

Based on the results from the presented investigation, this section describes conclusions regarding the physical processes responsible for DCA erosion in ring-cusp gridded ion thrusters. Figure 8 illustrates the physical erosion processes.

The double-layer plasma potential structure that couples the bulk and cathode plasmas focuses and drives ions toward the DCA. Some bombarding ions suffer CEX collisions with the neutral xenon atoms being expelled from the DCA, the products of which include a "slow" CEX-ion and a "fast" neutral. The CEX-ion is easily pulled toward the DCA keeper by the ambient electric field. However, CEX-ions are created at a lower potential than ions originating in the bulk plasma and therefore have a significantly lower bombarding energy $(\sim 10 \mathrm{~V}$ instead of $\sim 22 \mathrm{~V}$ for $\mathrm{Xe}^{+}$, and $\sim 12 \mathrm{~V}$ versus $\sim 44 \mathrm{~V}$ for $\mathrm{Xe}^{2+}$ ). Focusing on the $\mathrm{Xe}^{+}$case, the neutral xenon atom resulting from the CEX collision may also impact the keeper and cause erosion. However, the neutral is not accelerated through the plasma potential structure and therefore impacts the keeper with the pre-CEX 
ion energy $(\sim 12 \mathrm{~V})$. Therefore, the presence of CEX collisions decreases keeper erosion because a single high-energy bombarding ion from the bulk plasma $(\sim 22 \mathrm{~V})$ is substituted with two lower-energy particles: a CEX-ion $(\sim 10 \mathrm{~V})$; and a neutral atom $(\sim 12 \mathrm{~V})$. Each of the two resulting particles has lower energy than the initial ion and causes less erosion. In fact, the energy of each of the post-CEX particles may be lower than the threshold energy of the target material, in which case no sputtering erosion occurs.

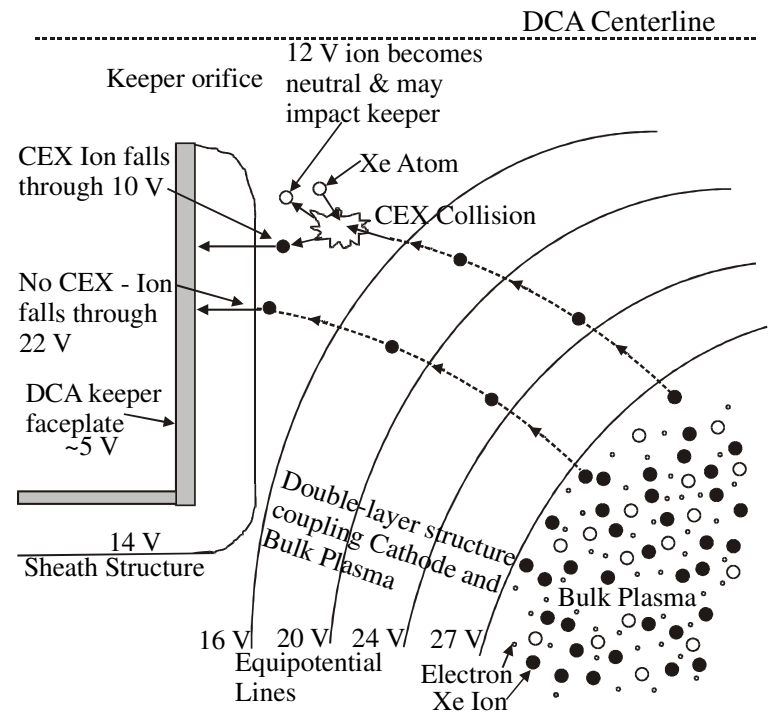

Figure 8: Schematic illustrating the DCA erosion processes. The double-layer structure coupling the bulk and cathode plasma pulls and focuses ions into the DCA. CEX collisions reduce ion bombarding energy.

The presence of doubles and the effect of shorting the keeper to common both have a significant effect on the DCA erosion rate. A doubleto-single plume current ratio of 0.25 has been measured in ion thruster plumes and the incorporation of doubles in the erosion calculation yields erosion rates that are consistent with the NSTAR wear test data. Particularly, the ELT erosion rate prior to throttling down the thruster, and during and after the shorting of the keeper to common are consistent with the predicted values.

The DCA erosion processes explain the ELT results and those presented by Kolasinski that show the primary erosion location shifting from the $50 \%$ keeper radius to the keeper orifice when thruster operation is changed from $\mathrm{TH} 15$ to $\mathrm{TH} 8$, respectively. At the onset of the ELT, the thruster is operated at TH 8 and then $\mathrm{TH} 15$, where it suffers erosion at the $50 \%$ keeper radius on the keeper downstream face (TH 15 erosion profile, Figure 5a). At $\sim 4,500$-h into the test, the thruster is adjusted to the lower-power lower-flow rate TH 8 operating point, which causes the erosion profile to shift due to the change in DCA flow rate. As such, erosion now occurs at the keeper orifice, leading to a chamfering profile (Figure 7). The cathode-to-keeper short at $\sim 6400$-hr only increases the erosion rate; the erosion profile is not affected. At $\sim 10,500 \mathrm{hr}$, the thruster is returned to $\mathrm{TH} 15$, but the keeper orifice has been eroded to twice its initial diameter. Although the DCA flow rate is increased upon returning to $\mathrm{TH} 15$, the keeper orifice is larger so the neutral number density does not return to the pre-TH 8 value. Because of the enlarged orifice and corresponding reduced neutral density, the orifice cannot protect itself with CEX collisions and erosion continues with the TH 8 profile even though the thruster is operating at TH 15. This erosion profile remains the same throughout the remainder of the ELT, eventually eroding away the entire keeper faceplate.

\section{Acknowledgments}

We thank Mr. Terry Larrow for fabricating the hardware used in this study, Mr. Michael Patterson of NASA GRC for the financial support of this research through research grant $\mathrm{NNC04GA67G} \mathrm{and} \mathrm{for} \mathrm{use}$ of government furnished equipment, and Dr. John Foster (grant monitor) who has been the principal contact at NASA GRC. We would also like to thank Dr. Darren Alman of Starfire Industries and Dr. David Ruzic of the University of Illinois for their input regarding the modeling portion of this work.

\section{References}

${ }^{1}$ Sovey, J. S., "Improved Ion Containment using a Ring-Cusp Ion thruster," Journal of Spacecraft and Rockets, Vol. 21, No. 5, pp. 488-495, Sept. - Oct. 1984.

${ }^{2}$ Patterson, M. J., Rawlin, V. K., Sovey, J. S., Kussmaul, M. J. and Parkes, J., "2.3 kW Ion Thruster Wear Test," San Diego, CA, July 10-12, 1995.

${ }^{3}$ Polk, J. E., Patterson, M. J., Brophy, J. R., Rawlin, V. K., Sovey, J. S., Myers, R. M., Blandino, J. J., Goodfellow, K. and Garner, C. E., "A 1000Hour Wear Test of the NSTAR Ion Thruster," Lake Buena Vista, FL, July 1-3, 1996.

${ }^{4}$ Anderson, J. R., Goodfellow, K., Polk, J. E., Shotwell, R. F., Rawlin, V. K., Sovey, J. S. and Patterson, M. J., "Results of an On-going Long Duration Ground Test of the DS1 Flight Spare Ion Engine," Los Angeles, CA, June 20-24, 1999. 
${ }^{5}$ Polk, J. E., Anderson, J. R., Brophy, J. R., Rawlin, V. K., Patterson, M. J., Sovey, J. S. and Hamley, J., "An Overview of the Results from an 8200 Hour Wear Test of the NSTAR Ion Thruster," AIAA-1999-2446, 35 ${ }^{\text {th }}$ AIAA/ASME/SAE/ASEE Joint Propulsion Conference and Exhibit, Los Angeles, CA, June 20-24, 1999.

${ }^{6}$ Polk, J. E., Anderson, J. R., Brophy, J. R., Rawlin, V. K., Patterson, M. J. and Sovey, J. S., "The Effect of Engine Wear on Performance in the NSTAR 8000 Hour Ion Engine Endurance Test," AIAA-1997-0869, 33 ${ }^{\text {rd }}$ AIAA/ASME/SAE/ASEE Joint Propulsion Conference and Exhibit, Seattle, WA, July 6-9, 1997.

${ }^{7}$ Sengupta, A., Anderson, J. R., Brophy, J. R., Rawlin, V. K. and Sovey, J. S., "Performance Characteristics of the Deep Space 1 Flight Spare Ion Thruster Long Duration Test after 21,300 hours of operation," Indianapolis, IN, July 7-10, 2002.

${ }^{8}$ Sengupta, A., Brophy, J. R. and Goodfellow, K., "Status of the Extended Life Test of the Deep Space 1 flight spare engine after 30,352 hours of operation," Huntsville, AL, July 20-23, 2003.

${ }^{9}$ Sengupta, A., Brophy, J. R., Anderson, J. R., Garner, C. E., de Groh, K., Karniotis, T. and Banks, B., "An Overview of the Results from the 30,000 $\mathrm{Hr}$ Life Test of Deep Space 1 Flight Spare Ion Engine," Fort Lauderdale, FL, July 11-14, 2004.

${ }^{10}$ Anderson, J. R., Goodfellow, K., Polk, J. E., Rawlin, V. K. and Sovey, J. S., "Performance Characteristics of the NSTAR Ion Thruster During an On-Going Long Duration Ground Test," Big Sky, MT, March 18-25, 2000.

${ }^{11}$ Kolasinski, R. D.Polk, J. E., "Characterization of Cathode Keeper Wear by Surface Layer Activation," Journal of Propulsion and Power, Vol. 20, No. 6, pp. 992-999, Nov.-Dec. 2004.

${ }^{12}$ Herman, D. A.Gallimore, A. D., "A high-speed axial reciprocating probe positioning system for interrogating the discharge plasma of a $30 \mathrm{~cm}$ ion thruster," AIAA-2002-4256, 38th AIAA / ASME / SAE / ASEE Joint Propulsion Conference, Indianapolis, IN, July 7-10, 2002.

${ }^{13}$ Herman, D. A.Gallimore, A. D., "Comparison of Discharge Plasma Parameters in a 30-cm NSTAR Type Ion Engine with and without Beam Extraction," AIAA-2003-5162, 39th AIAA / ASME / SAE / ASEE Joint Propulsion Conference, Huntsville, Alabama, July 20-23, 2003.

${ }^{14}$ Herman, D. A., McFarlane, D. S. and Gallimore, A. D., "Discharge plasma parameters of a $30 \mathrm{~cm}$ ion thruster measured without beam extraction using a high-speed axial reciprocating probe positioning system," IEPC-03-0069, 28th International Electric Propulsion Conference, Toulouse, France, March 17-21, 2003.
${ }^{15}$ Williams, G. J., "The Use of Laser-Induced Fluorescence to Characterize Discharge Cathode Erosion in a $30 \mathrm{~cm}$ Ring-Cusp Ion thruster," Ph. D. Thesis, Dept. of Aerospace Engineering, University of Michigan, Ann Arbor, MI, 2000.

${ }^{16}$ Williams, G. J., Smith, T. B. and Gallimore, A. D., "30 cm Ion Thruster Discharge Cathode Erosion," IEPC Paper 01-306, 27 ${ }^{\text {th }}$ International Electric Propulsion Conference, Pasadena, CA, October 1519, 2001.

${ }^{17}$ Williams, G. J., Smith, T. B., Hidaka, Y. and Gallimore, A. D., "FMT-2 Discharge Cathode Erosion Rate Measurements via Laser-Induced Fluorescence," $\quad$ AIAA-2000-3663, 36 ${ }^{\text {th }}$ AIAA/ASME/SAE/ASEE Joint Propulsion Conference and Exhibit, Huntsville, AL, July 17-19, 2000.

${ }^{18}$ Williams, G. J., Smith, T. B., Patrick, T. A. and Gallimore, A. D., "Characterization of the FMT-2 Discharge Cathode Plume," IEPC Paper 99-104, $26^{\text {th }}$ International Electric Propulsion Conference, Kitakyushu, Japan, October 1999.

${ }^{19}$ Herman, D. A., "The Use of Electrostatic Probes to Characterize the Discharge Plasma Structure and Identify Discharge Cathode Erosion Mechanisms in Ring-Cusp Ion Thrusters," Thesis, Dept. of Aerospace Engineering, University of Michigan, Ann Arbor, MI, 2005.

${ }^{20}$ Herman, D. A.Gallimore, A. D., "Near Discharge Cathode Assembly Plasma Potential Measurements in a $30 \mathrm{~cm}$ NSTAR-type Ion Engine amidst Beam Extraction," AIAA-2004-3958, 40 AIAA/ASME/SAE/ASEE Joint Propulsion Conference and Exhibit, Fort Lauderdale, FL, July 11-14, 2004.

${ }^{21}$ Hershkowitz, N., "Chapter 3: How Langmuir Probes Work," Plasma Diagnostics, O. Auciello and D. L. Flamm, eds., Academic Press, Inc., Orlando, FL, pp. 113-183,1989.

${ }^{22}$ Hershkowitz, N.Cho, M. H., "Measurement of Plasma Potential using Collecting and Emitting Probes," Journal of Vacuum Science and Technology A, Vol. 6, No. 3, pp. 2054-2059, May/June 1988.

${ }^{23}$ Hershkowitz, N., Nelson, B., Pew, J. and Gates, D., "Self-Emissive Probes," Review of Scientific Instruments, Vol. 54, No. 1, pp. 29-34, January 1983.

${ }^{24}$ Laframboise, J. G., "Theory of Spherical and Cylindrical Langmuir Probes in a Collisionless, Maxwellian Plasma at Rest," UTIAS 100, University of Toronto, March 1966.

${ }^{25}$ Langmuir, I., "The Interaction of Electron and Positive Ion Space Charges in Cathode Sheaths," Physical Review, Vol. 33, pp. 954-989, June 1929.

${ }^{26}$ Mott-Smith, H. M.Langmuir, I., "Langmuir Probe Theory," Physical Review, Vol. 28, pp. 727, 1926. 
${ }^{27}$ Kameyama, I.Wilbur, P. J., "Potential-Hill Model of High-Energy Ion Production near HighCurrent Hollow Cathodes," ISTS-98-a-2-17, 21st International Symposium on Space Technology and Science, Omiya, Japan, May 24-31, 1998.

${ }^{28}$ Foster, J. E.Patterson, M. J., "Plasma Emission Characteristics from a High Current Hollow Cathode in an Ion Thruster Discharge Chamber," AIAA-20024102, $38^{\text {th }}$ AIAA/ASME/SAE/ASEE Joint Propulsion Conference and Exhibit, Indianapolis, IN, July 7-10, 2002.

${ }^{29}$ Charles, C.Bowell, R., "Current-free doublelayer formation in a high-density helicon discharge," Applied Physics Letters, Vol. 82, No. 9, pp. 1-4, March 3, 2003.

${ }^{30}$ Coakley, P.Hershkowitz, N., "Laboratory Double Layers," Physics of Fluids, Vol. 22, No. 6, pp. 1171-1181, June 1979.

${ }^{31}$ Doerner, R. P.Goebel, D. M., "Sputtering Yields of Ion Thruster Grid and Cathode Materials during Very Low Xenon Plasma Bombardment," AIAA-2003-4561, 39th JPC, Huntsville, AL, July 20-23.

${ }^{32}$ Doerner, R. P., Whyte, D. G. and Goebel, D. M., "Sputtering Yield Measurements during Low Energy Xenon Plasma Bombardment," Journal of Applied Physics, Vol. 93, No. 9, pp. 5816-5823, May 1.

${ }^{33}$ Wehner, G., "Influence of the Angle of Incidence on Sputtering Yields," Journal of Applied Physics, Vol. 30, No. 11, pp. 1762-1765, November 1959.

${ }^{34}$ Cheney, K. B.Pitkin, E. T., "Sputtering at Acute Incidence," Journal of Applied Physics, Vol. 36, No. 11, pp. 3542-3544, November 1965.

${ }^{35}$ Tartz, M., Neumann, H., Fritsche, B., Leiter, H. J. and Esch, J., "Investigation of Sputter Behavior of Ion Thruster Grid Materials," AIAA-2004-4114, 40 AIAA/ASME/SAE/ASEE Joint Propulsion Conference and Exhibit, Fort Lauderdale, FL, July 11-14, 2004.

${ }^{36}$ Yamamura, Y., "An Empirical Formula for Angular Dependence of Sputtering Yields," Radiation Effects, Vol. 80, pp. 57-72, 1984.

${ }^{37}$ Yamamura, Y., "Threshold Energies of LightIon Sputtering and Heavy-Ion Sputtering as a Function of Angle of Incidence," Nuclear Instruments and Methods in Physics Research B2, pp. 627-630, 1984.

${ }^{38}$ Kolasinski, R. D., "Sputtering Yields of Ion Thruster Materials at Oblique Incidence," AIAA2004-4110, 40 ${ }^{\text {th }}$ AIAA/ASME/SAE/ASEE Joint Propulsion Conference and Exhibit, Fort Lauderdale, FL, July 11-14, 2004.

${ }^{39}$ Duchemin, O. B., "A Review of Low Energy Sputtering Theory and Experiments," IEPC Paper 97-
068, 25th International Electric Propulsion Conference, Cleveland, OH, Aug. 24-28, 1997.

${ }^{40}$ Anderson, J. R., Goodfellow, K., Polk, J. E., Rawlin, V. K. and Sovey, J. S., "Performance Characteristics of the NSTAR Ion Thruster During an On-Going Long Duration Ground Test," 2000 IEEE Aerospace Conference Proceedings, Vol. 4, pp. 123148, March 2000.

${ }^{41}$ Polk, J. E., Patterson, M. J., Brophy, J. R., Rawlin, V. K., Sovey, J. S., Myers, R. M., Blandino, J. J., Goodfellow, K. D. and Garner, C. E., "A 1000 Hour Wear Test of the NASA NSTAR Ion Thruster," AIAA-1996-2784, 32 ${ }^{\text {nd }}$ AIAA/ASME/SAE/ASEE Joint Propulsion Conference and Exhibit, Lake Buena Vista, FL, July 1-3, 1996.

${ }^{42}$ Domonkos, M. T., Foster, J. E. and Patterson, M. J., "Investigation of Keeper Erosion in the NSTAR Ion Thruster," IEPC Paper 01-308, $27^{\text {th }}$ International Electric Propulsion Conference, Pasadena, CA, October 15-19, 2001.

${ }^{43}$ Garner, C. E., Sengupta, A., Kulleck, J. G. and Liu, T. M., "An Evaluation of the Discharge Chamber of the 30,000 Hr Life Test of the Deep Space 1 Flight Spare Ion Engine," AIAA-2004-3609, $40^{\text {th }}$ AIAA/ASME/SAE/ASEE Joint Propulsion Conference and Exhibit, Fort Lauderdale, FL, July 11-14, 2004.

${ }^{44}$ Sengupta, A., Brophy, J. R., Anderson, J. R., Garner, C. E., de Groh, K., Karniotis, T. and Banks, B., "An Overview of the Results from the 30,000 $\mathrm{Hr}$ Life Test of Deep Space 1 Flight Spare Engine," AIAA-2004-3608, 40 ${ }^{\text {th }}$ AIAA/ASME/SAE/ASEE Joint Propulsion Conference and Exhibit, Fort Lauderdale, FL, July 11-14, 2004.

${ }^{45}$ Sengupta, A., Brophy, J. R. and Goodfellow, K., "Wear Characteristics from the Extended Life Test of the DS1 Flight Spare Ion Thruster," $28^{\text {th }}$ International Electric Propulsion Conference, Toulousse, France, March 17-21, 2003.

${ }^{46}$ Sengupta, A., Brophy, J. R. and Goodfellow, K. D., "Status of the Extended Life Test of the Deep Space 1 Flight Spare Ion Engine after 30,352 Hours of Operation," AIAA-2003-4558, 39 AIAA/ASME/SAE/ASEE Joint Propulsion Conference and Exhibit, Huntsville, AL, July 20-23, 2003.

${ }^{47}$ Domonkos, M. T., Foster, J. E. and Soulas, G. C., "Wear Testing and Analysis of Ion Engine Discharge Cathode Keeper," Journal of Propulsion and Power, Vol. 21, No. 1, pp. 102, January-February 2005.

${ }^{48}$ Williams, G. J., Domonkos, M. T. and Chavez, J. M., "Measurement of Doubly Charged Ions in Ion Thruster Plumes," IEPC Paper 2001-310, $27^{\text {th }}$ International Electric Propulsion Conference, Pasadena, CA, October 15-19, 2001. 
${ }^{49}$ Domonkos, M. T., Foster, C. and Soulas, G. C., "Wear Testing and Analysis of Ion Engine Discharge Cathode Keeper," Journal of Propulsion and Power, Vol. 21, No. 1, pp. 102-110, Jan.-Feb. 2005.

${ }^{50}$ Rovey, J. L., "A Multiple-Cathode, HighPower, Rectangular Ion Thruster Discharge Chamber for Increasing Thruster Lifetime," Doctoral Thesis, Dept. of Aerospace Engineering, The University of Michigan, Ann Arbor, MI., 2006.

${ }^{51}$ Rovey, J. L., Herman, D. A. and Gallimore, A. D., "Potential Structure and Propellant Flow Rate Theory for Ion Thruster Discharge Cathode Erosion," Princeton, NJ., Oct. 31-Nov. 4, 2005.

${ }^{52}$ Kameyama, I.Wilbur, P. J., "Effects of External Flow near High-Current Hollow Cathodes on IonEnergy Distributions," Cleveland, OH, Aug. 24-28, 1997.

${ }^{53}$ Domonkos, M. T., "Evaluation of Low-Current Orificed Hollow Cathodes," Ph. D. Thesis, Dept. of Aerospace Engineering, University of Michigan, Ann Arbor, MI, 1999.

${ }^{54}$ Boyd, I. D.Dressler, R. A., "Far field modeling of the plasma plume of a Hall thruster," Journal of Applied Physics, Vol. 92, No. 4, pp. 1764-1774, Aug. 2002.

${ }^{55} \mathrm{Oh}$, D. Y., "Computational Modeling of Expanding Plasma Plumes in Space Using a PICDSMC Algorithm," Doctoral Thesis, Dept. of Aeronautics and Astronautics, Massachusetts Institute of Technology, Cambridge, MA, 1996. 